\title{
Pancreatic Teratoma
}

National Cancer Institute

\section{Source}

National Cancer Institute. Pancreatic Teratoma. NCI Thesaurus. Code C95558.

A teratoma that arises from the pancreas. 